\title{
"A Review of Additive Manufacturing Technology and Cost Estimation Techniques for the Defence Sector"
}

\author{
Alessandro Busachia*, John Erkoyuncu ${ }^{\mathrm{b}}$, Paul Colegrove ${ }^{\mathrm{c}}$, Filomeno Martina ${ }^{\mathrm{c}}$, Chris Watts ${ }^{\mathrm{d}}$, Richard \\ Drake $^{\text {d }}$ \\ ${ }^{a}$ Through Life Engineering Services Centre, Cranfield University, \\ ${ }^{b}$ Operations Excellence Institute, Cranfield University, Cranfield, United Kingdom \\ ${ }^{c}$ Welding Engineering and Laser Processing Centre, Cranfield University, Cranfield, United Kingdomd \\ ${ }^{c}$ Babcock International, Bristol, United Kingdom
}

\begin{abstract}
Keywords: Technology Acquisition, Cost Estimation, Activity Based Costing, Additive Manufacturing, Defence Support Services * Corresponding author. Tel.:+447790779432; E-mail address: a.busachi@,cranfield.ac.uk

Abstract

"Additive Manufacturing" (AM) is a promising technology which will provide major advantages to Defence Support Service providers, given its ability of delocalised manufacturing near the point of use. The technology is gaining increasing interest due to its disruptive potential. AM groups together a wide range of different approaches which have the ability to convert a 3D file into a physical product by depositing layer upon layer of material. AM is still under development and considered an immature technology. This immaturity provides high level of uncertainty around key indicators such as time and cost. These indicators represent also key decision variables to evaluate AM and compare it with traditional manufacturing. This review paper represents an investigation of existing knowledge on AM and aims to present to the reader the various AM approaches with a detailed focus on the most applicable technologies to Defence Support Services. The paper is structured as follows, firstly the various technologies of AM and their economic aspects are presented, secondly the cost modelling techniques are investigated and finally a discussion is carried out. The contribution of this paper is to present to Defence Support Service stakeholders the various AM technologies and cost modelling techniques for measuring the product or service cost.
\end{abstract}

\section{Introduction}

Defence Support Service providers operate in safety and mission critical environments and are responsible for delivering integrated product and service solutions. These providers are responsible for maintaining one or more complex engineering systems under performance based contracts, which are typically measured with component, equipment or system availability. "Additive Manufacturing" (AM) is a promising technology, which builds components by adding layers of material and provides the ability to produce complex geometries without the need of extensive manufacturing systems. Due to its versatility and relative compactness, various Defence Support Service providers operating in the Defence industry are exploiting the opportunity to provide Platforms with AM capability. The main example is the USS Essex which has applied AM for printing drones and disposable medical supplies (US Navy, 2015) Having AM capability on a platform might provide advantages in mission critical environments with disrupted supply chains. To evaluate the technology, the costs and delivery time have to be evaluated. Given a wide range of AM technologies available this review paper focus on presenting the various approaches and outline the differences. Moreover, as cost represents the main critical variable, cost modelling techniques are presented and compared allowing the reader to choose the most appropriate one for this application.

Section 2 provides an overview of the research efforts on AM. Section 3 introduces AM technology and its constituent process methodologies. Section 4 covers existing cost modelling techniques and outlines the most suitable technique for AM product cost estimation. Section 5 outlines economic aspects of AM and compares them with traditional manufacturing techniques. In section 6 a discussion is carried out to justify the selection of the technology and cost modelling techniques. Finally section 7 concludes the paper and summarises what has been investigated.

\section{AM Research Effort and Journal selection}

To assess the current research on AM, an analysis of publications has been carried out on the SCOPUS database using "Additive Manufacturing", "Cost Modelling", "Cost Estimation", and "Support Services" as keywords. A total of 2,300 publications have been published during the period between 1997 and 2017. The review is based on a lower number of 
publications which has been selected due to their relevance to the research scope involving, Support Services, defence applications,

Most publications were conference and journal paper. Figure 2 outlines the research published per year. This graph is featured by two periods. The first one between 1997 and 2009 in which publications were relatively steady, the second period between 2009 and 2014 in which Additive Manufacturing research interest has grown dramatically from 69 to 873 publications. This is mainly a consequences of a growing awareness of governments, research institutes and companies on AM benefits.

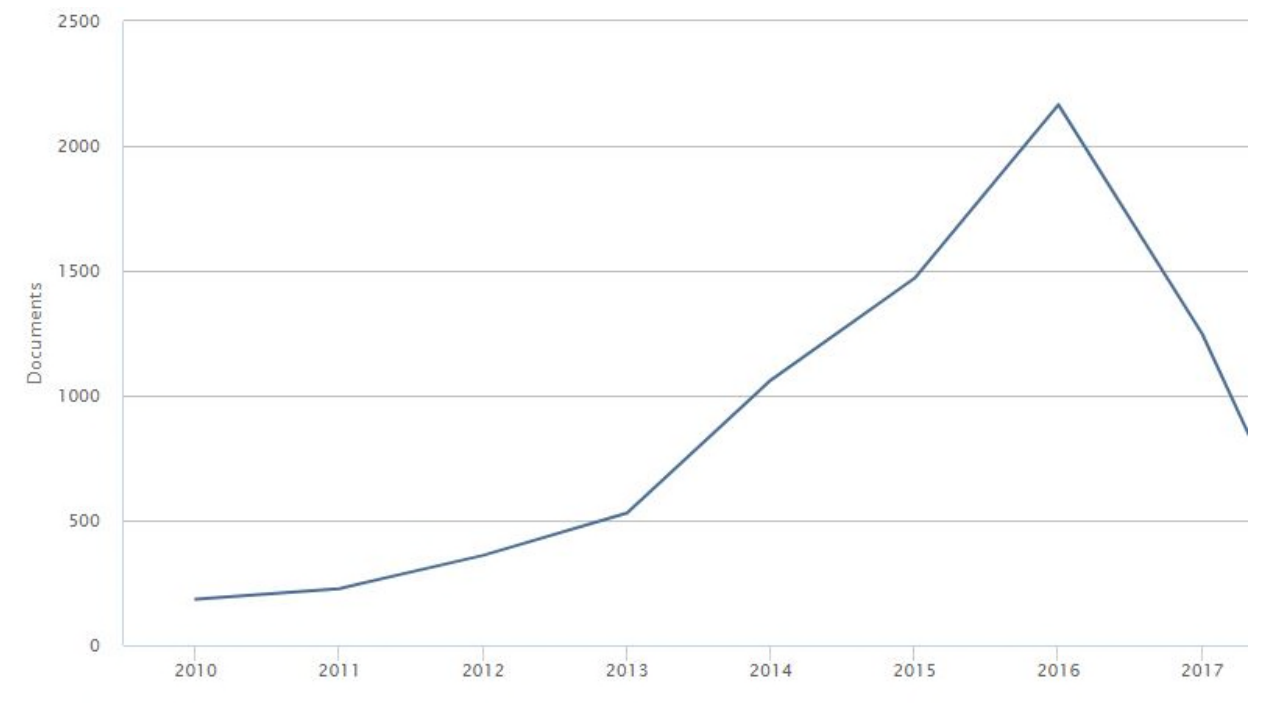

Figure 1 - AM Publication per Year

Loughborough University is leading the scene with a total of 92 publications, followed by the University of Texas El Paso with 65 publications and the Katholicke Universitaet Leuven with 54. Another interesting finding is the publication by country; United States is leading the scene with 961 publications followed by the United Kingdom with 300 and Germany with 281 . If the analysis is tailored to "Cost Modelling for Additive Manufacturing" the main Institutions which have mostly contributed to the research effort on estimating the costs of AM are: Loughborough University with 4 journal papers, Nottingham University with 1 conference paper for "Selective Laser Melting" (SLM), Cranfield University with $2 \mathrm{PhD}$ thesis for "Wire+Arc Additive Manufacturing" (WAAM). Another important contribution is made by the Universidad Politecnica de Catalonia which published a Neural Network model for time generation for Selective Laser Melting. Finally, the Naval Postgraduate School of California conducted research on AM implementation in US Navy platforms for supporting the systems with printing spares. Given the large amount of published journals on Additive manufacturing and related cost modelling techniques, a selection of information has been carried out. Firstly experts from the "Welding Engineering and Laser processing centre" of Cranfield have been identified and interviewed (Colegrove, Martina and Ding). Secondly the experts have provided the most relevant references of journals to be reviewed. Moreover references of the journals provided have been reviewed and included.

\section{Additive Manufacturing}

Ivanova et al. (2013) defines "Additive Manufacturing" (AM) as a group of emerging and promising technologies that create an object by adding material bottom-up. AM enables rapid conversion of CAD files into physical products by merging layer upon layer of heated material (RAND, 2013). It is defined as the "process of joining materials to make objects from threedimensional (3D) model data, usually layer by layer, as opposed to subtractive manufacturing methodology"(ASTM, 2013). As stated by Gao et al., (2015) "the term "additive manufacturing" was ultimately chosen by the ASTM F42 committee as it clearly distinguishes the processes from subtractive manufacturing techniques wherein material is removed from a workpiece As outlined by Campbell and Ivanova (2013), AM technology is a relatively simple process compared to traditional manufacturing which is labour intensive, requires more resources and complex processes such as machining, forging and moulding. 


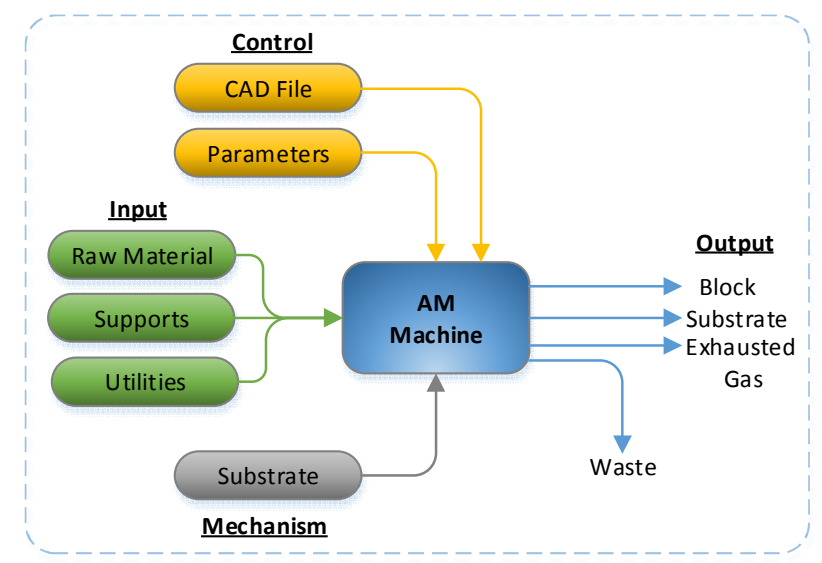

Figure 2 - IDEF0 representation of AM

As outlined in Figure 2 the inputs of AM are raw materials, supports and utilities. On the control side there is a CAD file which contains the geometry of the object and the parameters which can get up to 150 different variables. Parameters play a crucial role in the process as they have a strong incidence on object quality. On the mechanism side there is the substrate which is the plate on which the object will be grown. The substrate is usually made of the same material which will be deposited and is recyclable. The "American Society of Testing and Materials" (ASTM), issued in 2013 a standard for AM technologies. The aim of the standard is to group together current AM process methodologies. The result is a group of 7 different processes which absorb all different commercial variants of the technologies.

The standard definitions according to ASTM (2013) are:

Direct energy deposition: "process in which focused thermal energy is used to fuse materials by melting as they are being deposited".

$>$ Powder bed fusion: "process in which thermal energy selectively fuses regions of a powder bed".

$>$ Binder jetting: "process in which a liquid bonding agent is selectively deposited to join powder materials".

$>$ Material extrusion: "process in which material is selectively dispensed through a nozzle or orifice".

$>$ Material jetting: "process in which droplets of build material are selectively deposited".

$>$ Sheet lamination: "process in which sheets of material are bonded to form an object".

> Vat photopolymer: "process in which liquid photopolymer in a vat is selectively cured by light-activated polymerization"

Another important classification of AM is the one made by (Martina et al., 2015) which categorise the process methodologies based on energy source and feedstock type and outlines various possible configurations. Martina (2014) focuses on promising process methodologies for industrial applications therefore he does not include jetting, extrusion and lamination. Energy sources are arc and beam which are delivered through electrons or lasers. Feedstock can be wire or powder, on bed or blown. Moreover, he categorised the "Wire+Arc Additive Manufacturing" (WAAM), which is the research focus of Cranfield University. AM can be configured in various process methodologies based on components of the machine, feed type and energy source applied. Generally there are two main categories that differentiate the type of feed "Powder Bed Fusion" (PBF) and "Direct Energy Deposition" (DED) which are mainly based on wire feed (Martina et al., 2015). PBF and DED are also the most promising process methodologies for industry and Defence Support Service provider, therefore these have been investigated further and are the only one considered in the scope of the review. In Table 1 the main authors have been outlined and categorised based on their contribution towards the process methodologies. 
Keyword: “Additive Manufacturing” (AM)

Authors reviewed: Inova (2013), RAND (2013), ASTM (2013), Gao et al. (2015), Martina (2015), Martina (2014)

\section{Keyword: "Powder Based Fusion" (PBF)}

Authors reviewed: Gibson (2010), ASTM (2013), Arcam AB (2014), Jang et al. (2013), Safdar et al. (2007), NASA (2014), ASME (2012), Rafie et al. (2013), Loeber and Biamino (2012)

\section{Keyword: “Direct Energy Deposition” (DED)}

Authors reviewed: Wang et al. (2011), Ding et al. (2012), Qiu (2014), Chen (2012), Martina et al. (2012), Colegrove et al. (2013), Adebayo (2014), Taminger (2014), Seufzer (2013), NASA (2014), Stecker (2013), Taminger and Hafley (2010), Saqib et al. (2014), Gibson (2010), Fraunhofer (2014), Candel et al. (2014)

\section{"Powder Bed Fusion" (PBF)}

PBF process can be obtained by employing one at time different energy sources, laser beam or electron beam. Both processes share the same configuration for the feedstock which is based on a powder bed (Martina et al., 2015). The following schematic is a simplification of a PBF machine which outlines the main elements which are shared among all the commercial variants of $\mathrm{PBF}$.

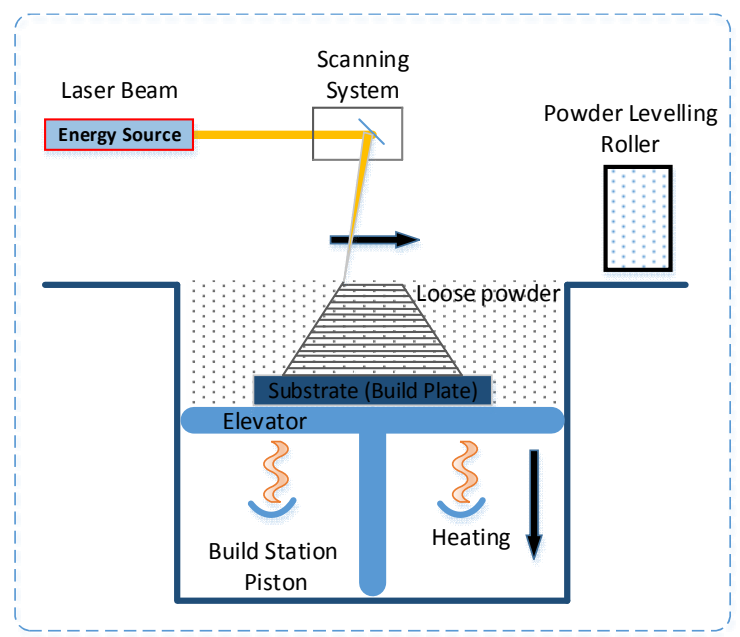

Figure 3 - PBF Schematic

According to Gibson (2010) the main elements are:

Energy Source: one or more sources of heat (Laser or Electron Beam) are necessary to induce fusion between the powder particles.

$>$ Scanning System: a method to control powder fusion to a prescribed region of each layer.

$>$ Powder Levelling: a mechanism for adding and smoothing powder layer.

D Elevator: a mechanism to control the lowering of the component in order to achieve growth through additional layers.

> IR Lamp: infrared lamp is necessary to pre-heat the powder before it is in contact with the Beam. (Higher powder temperature minimise Beam power requirements). 
$>$ Enclosed Chamber: this is necessary to create a controlled environment free from oxygen to eliminate oxidation of the material being fused/sintered.

The "Laser Sintering" (LS) technology is defined by ASTM (2013) as "a Powder Bed Fusion process used to product objects from powdered materials using one or more lasers to selectively fuse or melt the particles at the surface, layer by layer, in an enclosed chamber". There is a lack of formal definition of "Electron Beam Melting" in ASTM (2013) the main difference is the heat source, other process features remain the same. Arcam AB (2014) defines it as a "process in which fully dense metal components are built up, layer by layer from melted powder by a powerful electron beam”. According to Tong et al. (2013) alternative energy sources can result in different thermal distributions which influence the microstructure changes and the residual stress of the part. Moreover, Safdar et al. (2007) has demonstrated the impact of beam geometry and concluded that it affects the temperature distribution, melt pool geometry, heating/cooling rates and fluid flow velocity. NASA (2014) deduced that shape of the emery beam is important and has to be controlled using Faraday Cup calibration. Finally, ASME (2012) demonstrated that larger beam diameters results in lower temperatures in the molten pool for the same energy inputs. Rafi et al. (2013) compared EBM and SLM processes to manufacture a component in Ti6Al4V. The aim of the work was to evaluate the impact of these two technologies on mechanical properties and microstructure evolution. The results are that SLM leads to a microstructure composed of $\alpha$ martensitic phase while EBM mainly an $\alpha$ phase and minor parts of $\beta$ phase. This results in differences in tensile and fatigue properties due to cooling rates experienced. The SL samples have a higher tensile strength and better fatigue properties. According to Rafi et al. (2013) SLM processes are featured with high scanning speeds and higher thermal gradient which leads to high cooling rates which consequently results in a non-equilibrated microstructure. In EBM, the building chamber is preheated at $700^{\circ} \mathrm{C}$ with the advantage of minimizing the thermal induced residual stress and the formation of non-equilibrium microstructures. The main advantage of EBM is the high beam intensity which leads to greater efficiency of the process and slower production times (Rafi et al., 2013). Loeber and Biamino (2011) carried out an investigation of microstructure and mechanical properties of components of TiAL2Cr2Nb produced with SLM and EBM. They concluded that there are some differences on the samples processed by the different technologies. First of all, as EBM works under vacuum and the powder is preheated, the final density of the component is higher compared with the one processed with SLM. EBM sample has a density of $98 \%$ and featured only small spherical pores and its mechanical properties are comparable to the components processed with traditional manufacturing. Instead, the SLM component reached $97 \%$ of density, featured with unmolten areas and small crack can be observed. As the SLM component has traces of residual porosity, the mechanical performance of the structure is poor. Loeber and Biamino (2011) outlined that the experiment with the SLM component required an optimization study of the parameters and also the implementation of a heater to reduce the thermal tension during the rapid cooling of the component. This review of the two technologies is not sufficient to make a proper comparison and the only conclusion that can be drawn is that as EBM works under vacuum it has the assurance to process without oxygen impurities but it is subject to vaporization of elements due to the related high impact of the heat input.

\section{"Direct Energy Deposition" (DED)}

Direct Energy Deposition has different energy sources. It can employ laser beam, electron beam, or plasma variants such as TIG, MIG or plasma torches. Moreover it is not possible to outline a general machine element description.

\section{"Wire+Arc Additive Manufacturing” (WAAM)}

According to Ding et al. (2011) "Wire and Arc Additive Manufacturing" (WAAM) is gaining industry attractiveness for the production of large, custom made, near-net-shape metal components due to its versatility and high deposition rates. As defined by Wang et al. (2011) WAAM is an additive manufacturing process which uses TIG, MIG or Plasma torches to manufacture components by adding sequential layers of material from a wire feedstock without the need of tooling. The system is made of a power source which is the welding machine, a motion control system which is the robot, the torch for controlling the arc, a wire feeder and a chamber. Qiu, (2014) outlined several advantages of WAAM process such as the possibility to process super alloys, creation of large parts, high deposition rates, reduction of residual stress due to on-line rolling process. Chen (2012) stated that this technology can reduce BTF ratio by $30 \%-40 \%$. The results were impressive as the implementation of WAAM process could save around 3,000 tons of material. Ding et al. (2011) carried out a thermo-mechanical analysis of large scale components produced with WAAM process. They concluded that the stress across the deposition area is uniform while the part is clamped. Furthermore they outlined that after unclamping of the work, the stress is redistributed (Ding et al., 2011). Martina et al. (2012) carried out an investigation of the benefits of WAAM process based on plasma deposition for the manufacturing of Ti6A14V components for aerospace industry. They demonstrated the feasibility of the process for large aerospace structural components, defined a process envelop outlining the correct combination of process parameters. Nevertheless Martina et al. (2012) outlined that oxidation and distortion could become an issue. Currently, Cranfield's Welding Engineering and Laser Processing Centre developed a new process called Rolled WAAM which shares the same principle of WAAM process with the extension of a roller tool which performs on-line deformation to decrease the residual stress of the 
component. Colegrove et al. (2013) outlined that components processed with WAAM have strong distortion, residual stress and large grain size. This is mainly due to the high heat input of the arc. There is a need to develop mitigation methods to increase the quality of the components. After performing experimentations Colegrove et al. (2013) concluded that the rolling process can significantly reduce the peak of residual stress and distortion of the material. Moreover "slotted" rollers limit the lateral deformation of the sample with a better reduction in residual stress and distortion compared to the "profiled" roller. Another important conclusion which has a significant impact in terms of lead time is that if, the rolling activity is performed every four layers, it has a similar result compared to rolling every layer. Rolling has a significant impact on the microstructure of the samples. Colegrove et al. (2013) states that rolling enhances the grain refinement. Adebayo (2014) has studied the implication of solid lubricant application during the process. They concluded that also after cleaning the surface with Acetone, the traces of lubricant are still present and they affect the microstructure and hardness of the deposited material. More precisely the presence of lubricant increases the grain size and consequently reduces the hardness of the material. There is a need to identify the correct procedure and lubricant for applications such as rolling and machining of WAAM deposited material.

\section{"Electron Beam Additive Manufacturing" (EBAM)}

"Electron Beam Additive Manufacturing" or "Electron Beam Free Form Fabrication" (EBF3) as called by NASA, is a technology which uses an electron beam as a heat source and wire as feedstock. Invented at NASA Langley Research Centre, this technology is highly considered by numerous aerospace organisations such as Airbus, Lockheed Martin, Boeing and NASA. This is due to its high potential and for its ability to achieve high deposition rates, process large parts, achieve near-net shape depositions but most of all complex geometries (Taminger, 2014). As outlined previously, the electron beam needs to operate in a vacuum chamber to avoid collision of electrons with other particles and also to limit the oxidation of the melted pool. According to Seufzer (2013) EBF has been extensively tested on numerous practical applications by NASA and a miniature version of an EBF system has been installed and run aboard a NASA reduced gravity aircraft. Nevertheless, this technology is highly complex and is still being developed. As it has a wide range of parameters, there is still a need to understand the correlation of these. Most important parameters are: beam energy distribution, spot size, travel speed, wire feed rate, diameter, material composition, beam focus, deposition strategy and post processing activities such as thermal treatments. Moreover, as explained by Taminger (2014) the technology still has some problems such as the volatilization of elements such as Aluminium. This is due to the high vacuum environment in which it operates. There is a need to find optimal parameters to reduce Aluminium losses by reducing heat input. Other areas of improvement are related with quality assurance issues such as probe analysis to monitor beam degradation and process control tools to monitor the melt pool size and in case of excessive variance a tool to correct it (Taminger, 2014). Recently, NASA (2014) issued a state of the art literature review on EBF3 to assess the progress of the research on the technology. The finding were various and related to process and modelling efforts. There is still a lack of understanding of the relations between the process parameters: "there is no unifying equation or other understanding that reveals mastery of the process" (NASA, 2014). According to Stecker (2013) EBF3 has multiple advantages over Laser and wire based processes such as: the electron beam is electronically focusable and the output is scalable which allows to process fine details with low deposition power. The electron beam process is highly electrical efficient as it can reach up to $99 \%$ of efficiency while laser has a low level of efficiency such as $30 \%$ or lower. EBF3 is intended for the production of large near-net-shape functional components, specifically made of some complex engineering alloys. As demonstrated by Stecker (2013), this technology has significant cost savings compared to conventional processes. This is mainly due to the reduction of waste of raw materials and the reduction of lead times. EBF3 is currently ready for commercialisation; companies such as Sciaky are already manufacturing EBF3 systems. NASA Langley is working on the process to refine it and make it more robust (Taminger, 2014). As stated by NASA "although further process development and understanding is required, no barriers are evident to prevent the maturation of EBF into a competitive commercial process" (Taminger and Hafley, 2010).

\section{"Laser Cladding"}

Laser Cladding is defined as "a process which is used to fuse with a laser beam another material which has different metallurgical properties on a substrate, whereby only a very thin layer of the substrate has to be melted in order to achieve metallurgical bonding with minimal dilution of added material and substrate in order to maintain the original properties of the coating material" (Saqib et al., 2014). The previous definition outlines that the primary function of Laser Cladding is to be a method for deposition of coatings on surfaces. This technology is highly flexible and accurate and is able to obtain fully dense part. For this reason it is widely used also in the repair business of complex components such as turbine blades and is also suitable to produce directly a complete component. In case of "Laser Direct metal Deposition" the technology is used to deposit near-net shape final parts. The configuration of a coaxial deposition nozzle is made of 3 independent channels for laser beam, powder feed and finally shielding gas to protect the melt pool from oxidation. According to Gibson (2010) this configuration enables a higher capture efficiency of powder compared to other solutions. The coaxial deposition nozzle plays a major role in the process. This is because it highly affects powder consumption, oxidation of the substrate and also the final roughness. 
According to Fraunhofer (2014) this type of nozzle has various advantages such as higher deposition rates and powder utilization and most of all it has the ability to move in all directions in continuous operation. This technology has a wide range of application such as engine manufacturing for aerospace and automotive, plant engineering and machine-tool. As stated before the technology has two main functions, surface property enhancement and repair and remanufacturing. Optomec has developed also a commercialised product called LENS Print Engine which is a modular form for integration into working platforms. This solution allows the final client to purchase a low cost solution for AM applications. It works with 3 main elements a steady flow powder feeder, a precision flow deposition head and 3) a LENS process control system. Candel et al. (2014) observed that the most important combined parameters, related with final deposition quality are specific energy and powder density.

\section{Cost Modelling Techniques}

Product Cost estimation play a significant role in the evaluation of AM. It represents the basis to develop the key decision variable on $\mathrm{AM}$, which is the cost of product. Cost estimation is directly linked to business performance. Overpricing may result in a loss of sale while under-pricing may lead to a financial loss. Niazi et al. (2006) performed a detailed review of the state of the art in Product Cost Estimation covering exhaustively the various techniques available today. The following sub heading will cover "Intuitive Techniques", "Analogical Techniques" and "Analytical Techniques".

\subsection{Intuitive Techniques}

Case Based Reasoning technique adapts past design information collected from a database to the new design. It uses past experience to synthesise new design (Niazi et al., 2006). Ideally the old and new design should have strong similarities. Often this does not occur and changes to parts and assemblies need to be carried out. Missing information and data has to be collected and implemented. This process of improving the design is carried out until the design conforms the specifications. Ahn et al. (2014) suggests that to increase the estimate accuracy, it is necessary to prioritise the attribute impact within the model. This is supported by An et al. (2007) which demonstrated that by eliciting domain knowledge from experts and performing weight of attributes will result in a more accurate and reliable estimate. This approach is particularly suitable in early stages design such as the conceptual stage. Decision Support techniques are particularly suitable for evaluating design alternatives and they are developed to assist the estimator during the decision making process. Data and information are provided by a database which stores knowledge of experts and artificial intelligence is used to orient this knowledge toward problem solving (Niazi et al., 2006). There are three main categories of Decision Support Systems defined by Niazi et al. (2006): Ruled Based System which "are based on process time and cost calculation of feasible process from a set of available ones for the manufacture of a part based on design and/or manufacturing constraint". Fuzzy Logic Systems: particularly helpful in managing uncertainty and get reliable and accurate results. They are not appropriate for complex results as they require lot of effort. Expert Systems: are defined as "a system based on storing expert knowledge and manipulate it based on demand. The systems aim to mimic human expert with an automated logical reasoning approach.

\subsection{Analogical Techniques}

Regression analysis techniques are based on the use of historical data to establish a relationship between the product cost of past designs and the values of certain selected variables. This relationship is used to forecast the cost of the new design. They have well defined mathematical background which makes this technique very reliable. The aim is to investigate the contribution of each variable to the overall cost. Significant variables are identified through statistical test and are combined into Cost Estimation Relationships (CERs). Major advantage of this technique is the ability to interpret the relationship between variables and costs. In order to achieve this, there has to be a linear relationship between independent variables and costs. Moreover the variables need to be independent from each other (Verlinden et al., 2008).

Table 2 - Cost Estimation Technique Comparison

\begin{tabular}{|lll|}
\hline Technique & \multicolumn{1}{c}{ Advantages } & \multicolumn{1}{c|}{ Disadvantages } \\
\hline \multirow{4}{*}{ Intuitive } & -Quick to produce and flexible & -Prone to bias and error \\
& -few resources in terms of time and costs & -Inconsistent and unstructured process \\
& -Can be accurate as other more expensive & -Nondeterministic as each expert reaches different \\
& methods & estimates \\
& -Can provide optimised results & -Dependent on part designs \\
& -Handles uncertainties & -Time consuming \\
& -Quicker, more consistent and reliable result & -Might require complex programming skills \\
\hline
\end{tabular}




\begin{tabular}{|c|c|c|}
\hline \multicolumn{3}{|c|}{$\begin{array}{l}\text { References reviewed: (Rehman and Guenov, 1998) (Shehab and Abdalla, 2002) (Gayretli and Abdalla, 1999) (Shehab } \\
\text { and Abdalla, 2001) }\end{array}$} \\
\hline Analogical & $\begin{array}{l}\text {-Reasonably quick and based on actual data } \\
\text {-Few data required } \\
\text {-User knows the origin of the estimate } \\
\text {-No requirement of full understanding of } \\
\text { problem } \\
\text {-Accurate } \\
\text {-Simple method and deals with uncertain and } \\
\text { non-linear problems }\end{array}$ & $\begin{array}{l}\text {-Subjective adjustment } \\
\text {-Accuracy depends on similarity of items } \\
\text {-Difficult to assess effect of design change } \\
\text {-Blind to cost drivers } \\
\text {-More difficult than parametric method } \\
\text {-Does not handle innovative solutions } \\
\text {-Completely dependent on data }\end{array}$ \\
\hline \multicolumn{3}{|c|}{ References reviewed: (Pahl et al., 2007) (Cavalieri et al., 2004a) (Man-Yi Chen and Ding-Fang Chen, 2002) } \\
\hline Ana & $\begin{array}{l}\text {-More accurate than analogy and parametric } \\
\text { methods } \\
\text {-Detailed breakdown useful for negotiation } \\
\text {-Suitable when all characteristics of product and } \\
\text { production process are well defined } \\
\text {-Alternative process plans can be evaluated to get } \\
\text { optimised results } \\
\text { Easy and effective method using unit activity } \\
\text { costs }\end{array}$ & $\begin{array}{l}\text {-Slow execution } \\
\text {-Detailed data may not be available } \\
\text {-Inappropriate for estimation at design stage } \\
\text {-Detailed cost information required about resource } \\
\text { consumed } \\
\text {-Requires detailed design information } \\
\text {-Requires lead times in early design stage } \\
\text {-Time consuming requires detailed design and } \\
\text { process planning data }\end{array}$ \\
\hline
\end{tabular}

Back Propagation Neural Networks or Artificial Neural Networks (ANN) is an Artificial Intelligence approach which can be applied to investigate the Multi- and Non Linear- relationships of elements. These techniques are suitable for cost estimation problems in the early stage of a design process. The accuracy of the estimates can achieve good accuracy levels even when adequate information and data are not available (Niazi et al., 2006). The main advantage of ANN is that they do not require production process and product characteristics to be well defined. They are considered the last generation of tools for Product Cost Estimation and they are based on imitating the behaviour of experts when determining the main variables that rules the cost estimation (Duran et al., 2012). One of the key features of ANN is that they are able to identify the relationships between product features and costs. Vouk et al. (2011) explains that ANN works on the principle of establishing a relationship between input and output which is defined as a set of rules. The developer has to train the ANN which will learn these relationships and based on this when inputs are changed, the ANN can predict the outputs.

Parametric models express cost as a function of its constituent variables (Niazi et al., 2006). Cavalieri et al. (2004) explains that these variables are usually associated with the cost drivers, which are features of the product such as its performance, morphology and material. The cost estimating relationships (CERs) are the mathematical form which comprise all the variables/cost drivers and are expressed as a function. In order to develop the CERs, the parameters of the product which best explain its associated cost need to be identified. Secondly the historical data of this cost has to be normalised as companies are changing, learning and improving and also currency value is constant. Finally the mathematical function has to be developed.

\subsection{Analytical Techniques}

Feature Based Costing aims to identify the feature of the products which are associated with cost. Usually these features are related or with the design, such as the design complexity or with the related processes needed to achieve certain standards of quality (Niazi et al., 2006). Little work has been carried out on Feature Based Costing due to its little flexibility.

Operation Based Costing requires a wide range of data and information. They are not suitable for early design stage but perform well in the final stages when most of the information is available. The logic behind this method is identifying all the activities involved in the manufacturing process and outline a time for each activity. They also take into consideration setup times and non-productive times (Niazi et al., 2006).

Tolerance Based Costing is based on estimating the cost by considering the design tolerances of the product as a function of the product cost. Usually the estimation process is carried out with three models: 1) unit cost of production model, 2) quality model and finally 3 ) lead-time model. The aim is to obtain the best tolerances and outlining a range of suitable design variables. 
Activity Based Costing $(\mathrm{ABC})$ calculates the cost occurred in performing a manufacturing operation. This approach provides the ability to proportionally distribute the overheads over the activities involved in the production of the product (Niazi et al., 2006). According to Carli and Canavari (2013) the methodology has been developed to face the increasing level of fixed costs in modern companies. ABC "measures costs and performances of activities, resources and cost objects, assigns resources to activities and activities to cost objects based on their use" (Carli and Canavari, 2013).

\section{Cost Modelling for Additive Manufacturing}

Major contributors to cost modelling for AM are Hopkinson and Dickens (2003), Ruffo and Hague (2007), Lindemann (2012) which focused on "Powder Bed Fusion" (PBF) methodologies while Zhai (2012) for "Wire+Arc Additive Manufacturing" (WAAM) a "Direct Energy Deposition" (DED) technology. All approaches are based on Activity Based Costing, Lindemann (2012) outline that its major advantage is the consideration of different influence factors on the basis of the use of resources. Lindemann (2012) model, based on ABC helped to better understand the cost structure of a product built through AM.

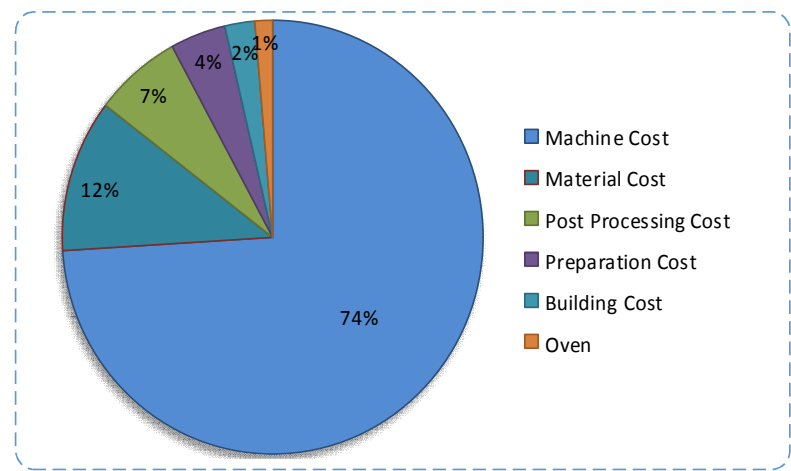

Figure $4-\overline{A M}$ Cost Structure, source: Lindemann (2012)

As the model is based on ABC cycle times of machines play a crucial role. The major cost driver is the machine cost which represents $74 \%$ of the total product cost. In a second simulation based on a deposition of $20 \mathrm{ccm}$ per hour, machine cost dropped to $46 \%$. Machine cost is followed by material cost which consist of the powder of metals. Currently the metal powder industry is unable to benefit from economies of scale and powder costs are relatively high. In the future metal powder demand will increase dramatically allowing producers to achieve more competitive prices (Mellor et al., 2014). Remaining costs are post processing to achieve material quality required, preparation cost which refers to all the data processing activities, oven cost and building process. Thomas and Gilbert (2014) outlined that the hidden benefits of AM need to be investigated and outlined in order to provide an exhaustive approach to better understand AM implications.

Lindemann, (2012) and Ruffo and Hague, (2007) have broken down the deposition process into its consituent elements and they associated an occurring cost with an activity. Therefore time represents the most important variable as it will influence dramatically all the results. According to Lindemann (2012) the deposition process is brokendown into preparation, deposition, removal of product and post-processes. This structure lacks details and might not be so representative of the real world. Lindemann (2012) emphasise that the estimation of the deposition time is the most important factor as it is the major influencer of total cost. Ruffo and Hague (2007) divided the deposition process into its operations such as time to add a layer, time to preheat the layer, time of scanning, and time to cool down. The sum of these times will provide the cycle time of the machine. Zhai (2012) estimated the product cost of the "Wire+Arc Additive manufacturing" process. Zhai (2012) developed the model to make a comparison between the manufacturing of a component by adding material with WAAM and by removing material from a block with CNC. The application of the component is for aerospace industry which seeks to adopt lower buy-to-fly ratios due to high costs of materials and high scraps.

The focus of the research was to investigate the impact of the two processes on buy-to-fly ratios. The results provided sufficient data to outline the major advantage of the WAAM process in near net shape manufacturing compared to CNC. The authors used as case study a Titanium part of the volume of $1,400 \mathrm{~cm} 3$. For the CNC solution a billet of $6,400 \mathrm{~cm} 3$ was required. Results showed that the WAAM deposition required 3.7 hours for a near-net shape deposition with a deposition rate of $0.9 \mathrm{~kg} / \mathrm{h}$ and 0.5 hours of milling to achieve a net-shape part and the CNC solution required only 1.3 hours. Nevertheless the advantage relies in the material cost saving which are for WAAM only $£ 750$ and for CNC $£ 1700$. Finally the total cost of the product printed with WAAM is $£ 1,800$ and with $\mathrm{CNC} £ 2,150$. 
As it is outlined in Figure $\mathbf{5}$ a deposited wall with WAAM is featured by two areas, the total wall area and the effective wall area. The difference between these two areas is the waviness which is a non-active part which will be removed with CNC. The deposition efficiency is calculated through a ratio of effective wall area over total wall area. Generally WAAM components have a deposition efficiency of $93 \%$ (Martina et al., 2012). The remaining 7\% is made of previous stated waviness.

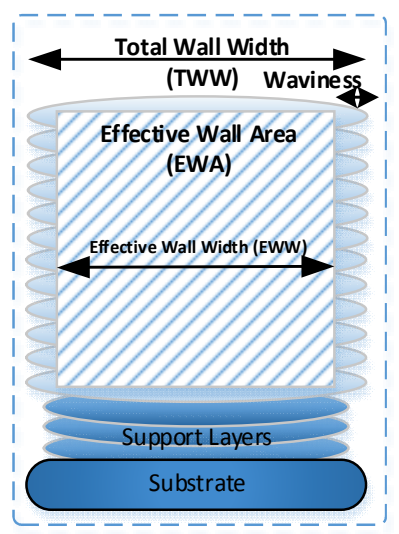

Figure 5 - WAAM Wall

The results on the cost structure were dramatically different from the results of PBF process methodologies. Due to lower capital investment and higher deposition rates (i.e. titanium $3 \mathrm{~kg} / \mathrm{h}$ and SS $10 \mathrm{~kg} / \mathrm{h}$ ) major contributor to product cost is setup cost $28 \%$, followed by welding material $27 \%$ and welding cost $25 \%$. An additional aspect outlined is the configuration of the machine which can be independent or integrated in which WAAM and the CNC machine are combined. The integrated configuration allows reducing dramatically the setup costs. Moreover, Zhai (2012) outlined that by increasing wire feed speed and a related energy density, this will reduce dramatically the total cost of WAAM. The wall has to rely on few layers of supports when the component and the substrate are not combined. The supports layers represent the location for the cutting and separate the substrate from the component. The following section will investigate economic aspects of Additive Manufacturing, providing the reader a deeper understanding on the financial implications of the technology.

The reviewed cost modelling approaches to estimate the cost of Additive Manufacturing are considered accurate for quick estimations. Nevertheless, they present some limits as AM requires significant pre and post processing activities such as powder handling and powder re-generation and sieving, support separation, milling and hipping to achieve the desired quality requirements. Moreover, none of the approaches reviewed consider in detail design activities for AM which involve investment in software packages to process the CAD file, topology optimisation packages to re-design the part, and design activities to identify the optimal orientation to minimise both the cycle time of the machine and reduce the volume of the supports.

\section{Economics of Additive Manufacturing}

Compared to traditional manufacturing methods, AM does not benefit from economies of scale. This is due to two main constraints, slow deposition rates and limited built capacity. According to Ruffo and Hague (2007) and Hopkinson and Dickens (2003) the behaviour of AM costs over units produced, benefit from an initial reduction in manufacturing costs but then the trend stabilises. 


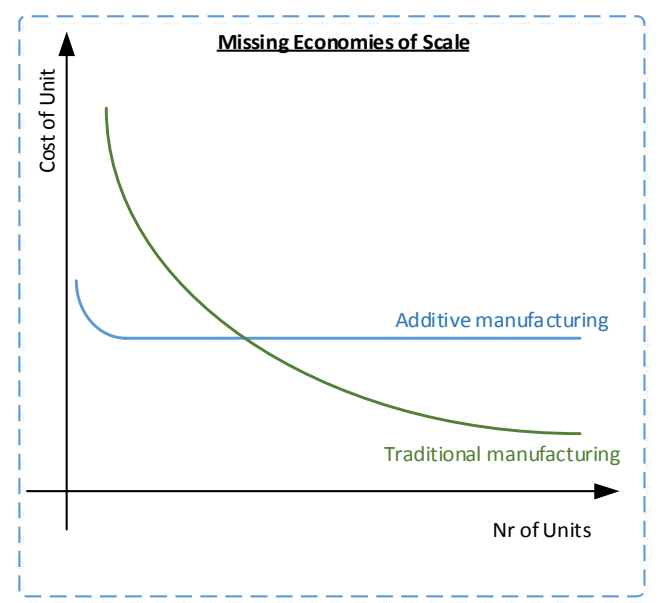

Figure 6 - AM Economies of Scale, source: Hopkinson and Dickens (2003)

According to Mellor et al. (2014) this might represent an advantage as mass production is shifting towards developing countries while EU and USA markets are focusing more on low volume and high value added productions featured with innovation, customisation and sustainability.

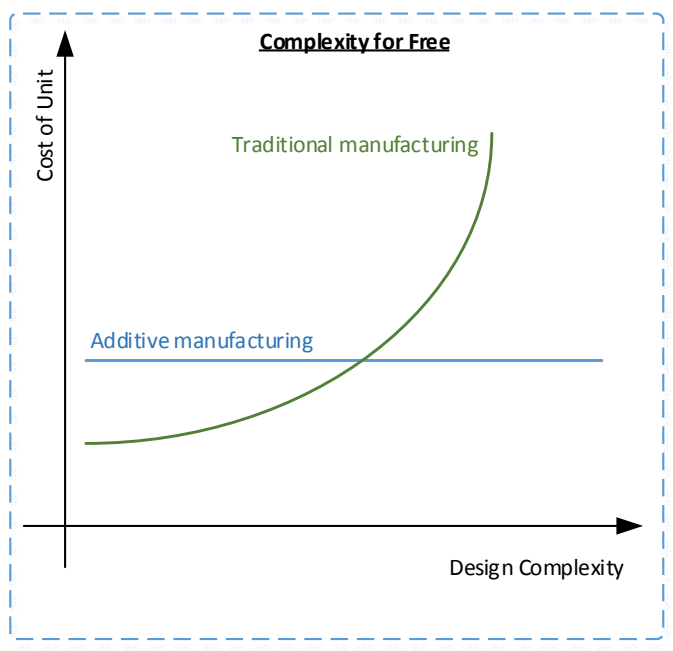

Figure 7 - AM Complexity for Free (Hopkinsons, 2003)

AM is considered a more suitable technology for economically sustainable small to medium volume productions. Moreover the technology allows design complexity for free, as outlined by Baumers (2012) AM inputs are not correlated to design complexity suggesting that financial production cost is independent to complexity. In traditional manufacturing methods, high level of customization might result in prohibitive manufacturing costs. This is due to high investment in modifications of the manufacturing line. This suggests that AM might have a higher product cost compared to traditional methods but if positioned correctly, the technology might give strategic advantages. For example in high value and technology advanced products. It is important to outline that complex geometries may require significant effort in developing adequate support structure to deposit the component. Moreover Zhai (2012) outlined the Buy-to-Fly ratio of the WAAM process. This index is an important measure to evaluate the suitability of a manufacturing process and it measures the material efficiency. The research showed that by reducing buy-to-Fly ratios manufacturing cost reduce dramatically. This is mainly due to an improved near net shape deposition involving reduced material scrap. Additionally Zhai (2012) outlines that WAAM process is particularly beneficial for Titanium depositions due to the high cost of this material. According to Roland Berger (2014), the forecast on deposition rates is promising, achieving up to $80 \mathrm{~cm} 3 / \mathrm{h}$ by 2023 , and making the technology more competitive in terms of cost and lead time. 


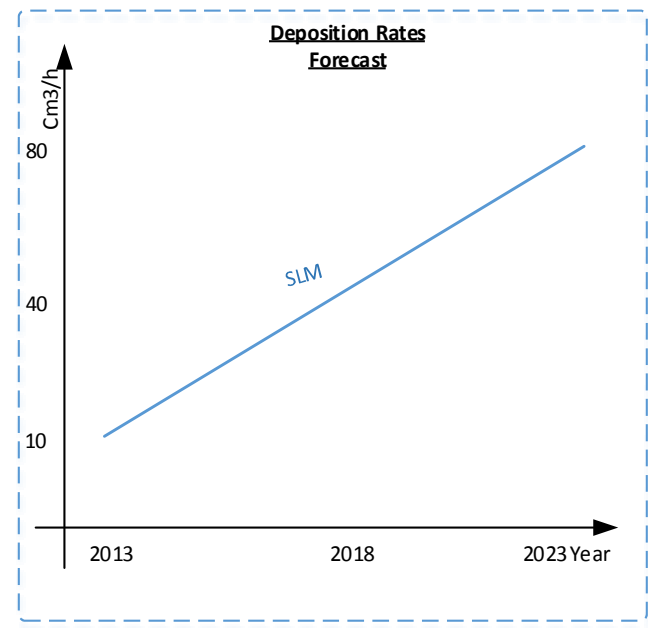

Figure 8 - Deposition Rate Forecast (Roland Berger, 2014)

Increasing deposition rates will have an impact on both, product cost and product cost structure. Lindemann, (2012) outlined a comparison of product cost structure with different deposition rates. By increasing deposition rate from $6.3 \mathrm{ccm} / \mathrm{h}$ to $20 \mathrm{ccm} / \mathrm{h}$ the incidence of the machine cost will drop from $75 \%$ to $48 \%$ providing a more competitive product cost. Higher deposition rates result in shorter cycle times of the machine. This implies lower human resources to be allocated to that product, providing more yearly capacity and improving responsiveness to demand. According to Roland Berger (2014) the current cost per cm3 is around 3.1 Euro and by 2023 it will drop to 1.1 Euro per $\mathrm{ccm}$.

\section{Discussion}

The literature review outlined that current AM technologies available on the market are: "Direct Energy Deposition", "Powder Bed Fusion", "Binder Jetting", "Material Extrusion", "Material Jetting", "Sheet Lamination" and "Vat Photopolymer". Powder based processes have higher cycle times and higher accuracy. These are employed for small to medium size components with extremely complex geometries for enhanced functionality. Wire based processes are faster but the accuracy level drops dramatically. Wire based solutions are employed for larger components in which accuracy levels are not the most important factor. Martina (2014) made a comparison of these two process methodologies for titanium applications. Powder based results are from a Selective Laser Melting machine while Wire Based results are from a "Wire+Arc Additive Manufacturing" machine.

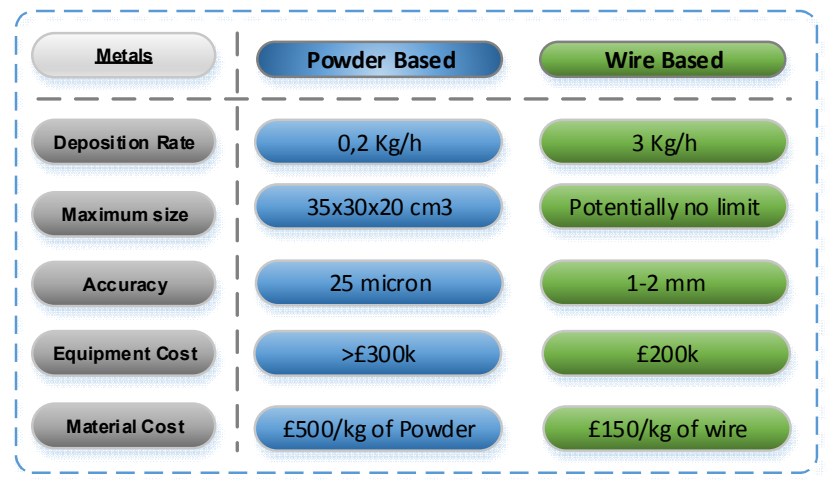

Figure 9 - Technologies comparison source: (Martina, 2015)

As it is outlined in Figure 9 the wire based solution has various advantages compared to the powder based solution. Lower investment cost, significantly higher deposition rates, lower costs of raw materials and no limits on build size make this solution particularly promising and attractive to industry. Figure 9 provides a typical example of Powder Based solution nevertheless there are more performing systems available in the market with higher accuracy and larger build chamber. Secondary advantages are related with the elimination of preheating phases, no vacuum required and therefore lower elements vaporisation. Powder based solutions provide the user with enhanced design freedom. The accuracy level, up to 25 micron, gives the designer the possibility to access any kind of geometry. Higher accuracy level implies lower deposition rates which 
in some situations has a strong impact on lead times. This might represent a barrier of powder based technologies. Deposition rates are influenced by energy density, scanning speed and layer thickness. Optimisation studies on these parameters are a focus study of Academia and Research Institutes in order to make these technologies more suitable for industrial applications. Moreover from the literature it was possible to outline product cost structure of the two different processes and results showed that in PBF methodologies, the major contributor to cost is the rate of the machine due to high investment cost and slow deposition rates. In the case of WAAM process, the major contributor to the cost structure is material followed by the cost of welding.

In order to measure costs related with AM depositions, various techniques have been investigated. According to Ruffo and Hague (2007) traditional cost modelling techniques have various disadvantages such as the inability to provide non-financial information which are critical to decision making. Moreover they lack of accuracy providing high uncertainties in the estimate. Generally Intuitive techniques are subjective and results may vary dramatically based on experts interviewed. Furthermore they are dependent on design features which in this case are not available. Analogical techniques are considered not fit for purpose as they depend heavily on data and in this case historical data is not available as the system is still in design phase. In order to achieve higher accuracy, wide range of information and a realistic and detail allocation of overheads, an analytical technique has been selected, "Activity Based Costing" (ABC). The literature states that this is the main technique used for cost modelling of AM. The technique assigns manufacturing overheads to activities in a more logical manner tackling the problems related with high overhead distribution. In addition $\mathrm{ABC}$ does not require historical data as the model can be developed based on process maps and interviews with experts. As outlined the main benefits of $\mathrm{ABC}$ is the allocation of costs according to where they are incurred improving accuracy and relevance. This allows detailing the cause of cost allowing the user to perform cost reduction analysis. In order to build the cost model, various documents have to be developed to gather all the necessary information and data required. The most important document as reported by Zhai (2012) is the process plan which outlines all the necessary manufacturing operations, the setup and unload activities and the post processes. This document organises the previous elements in a sequence and outlines the incurring times and resource consumptions. Another important document which needs to be developed is an IDEF0 map, as this provides details on inputs, output, controls and mechanism providing a more exhaustive approach to identify the sources of cost. In order to transform the data in cost, hourly rates of operators, machines and software has to be calculated. This can be done in different ways moreover the allocation of overheads may vary dramatically based on organisation type and has to be adapted on a case by case basis.

Through the literature review on AM, it was possible to define what are the opportunities provided by AM, these have been discriminated based on their nature and resulted in technical opportunities and operations opportunities. The classification has been carried out in the context of Defence Support Services for the Royal Navy.

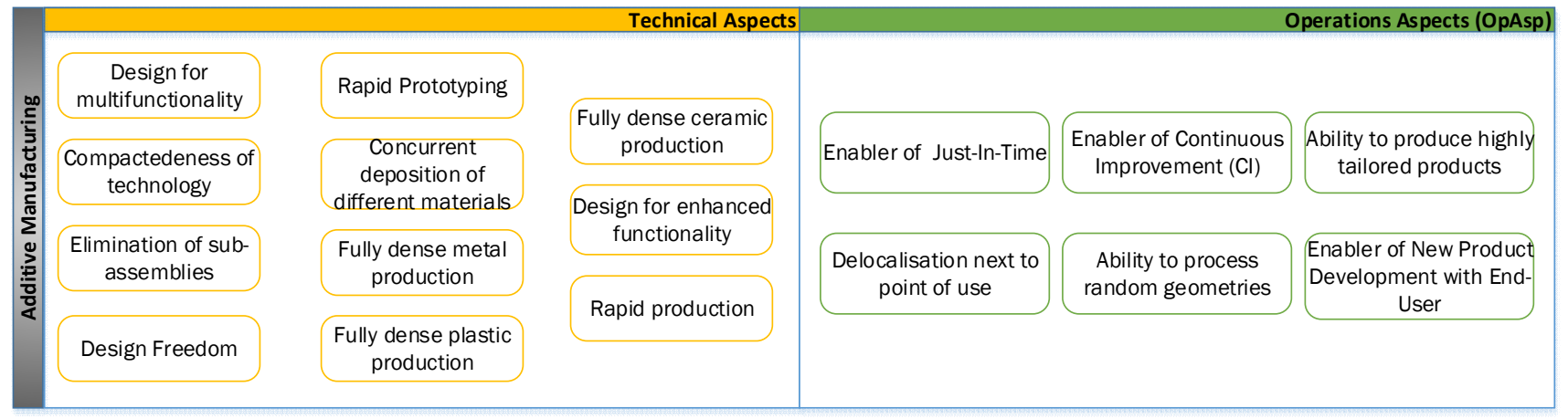

Table 3 - AM Opportunities

AM (generic) technical benefits have been outlined such as design freedom, compactness of technology, physical supply chain complexity reduction, digital supply chain, delocalisation, concurrent deposition of different materials, ability to process metals, plastic, ceramics and electronics, re-design for enhanced functionality or efficiency, elimination of sub-assemblies, multifunctionality, mass customisation. These benefits are shared with different levels, amongst most of the available process methodologies such as Laser Cladding (LC), Wire + Arc Additive Manufacturing (WAAM), "Fused Deposition Modelling" (FDM), "Selective Laser Melting" (SLM). AM (generic) operation aspects have been outlined. 
These AM operations aspect are based on "Manufacturing System Engineering", "Lean Manufacturing" principles and "Lean Product and Process Development" and are possible due to the delocalisation of AM production next to the point of use and through the involvement of the end-user:

$>\mathrm{AM}$ as an enabler of "Continuous Improvement" in the work place: RN operators, while deployed carry out their daily activities (with standard tools, jigs, equipment and kits) through which they mature a direct experience. During this experience they might develop/generate ideas in order to improve a process. If a platform has manufacturing capability based on AM they can convert ideas into functional products.

$>\mathrm{AM}$ is an enabler of Design Freedom, it is able to print rapidly any kind of geometry without the need to setup the machine or change tools: this aspect fits very well if we consider that AM is deployed in a platform to "serve" various "Complex Engineering Systems" (CES) made of an extended number of components which all differ one from another in terms of geometry. A sole AM machine is able to manufacture all of the components when these will fail.

$>\mathrm{AM}$ as an enabler of improved Product Development: similar to the first point, AM allows to improve the Product Development. End-users, through the utilisation or direct experience develop/generate naturally ideas to improve their daily routine. AM as an enabler of $\mathrm{CI}$ is given by a combination of delocalisation of manufacturing next to the point of use, involvement of end-user (which detain the direct experience) in the PD and rapid prototyping capability to test the designs in the early stage.

$>\mathrm{AM}$ as an enabler of "Just-in-Time" (JIT): Considering the delocalisation of manufacturing within the platform, the "Logistic Delay Time" (LDT) is eliminated or dramatically reduced, moreover AM allows to achieve short CT of production. This combination allows to establish JIT principles which allows you to reduce the stocks of finished goods and produce only the components that you require and when you require them.

$>\mathrm{AM}$ as an enabler of mass customisation: AM allows you to produce highly tailored products to your needs and unique features. This aspect is fundamental when you require special tools to perform an operation, when you have to produce a prosthesis tailored to the human body unique features or to provide special tools/small arms/body armours to tier-1 operators.

$>\mathrm{AM}$ as an enabler of improved Defence Support Services: through the delocalisation of AM within a platform, DS2 systems improve dramatically in terms of efficiency and cost.

The context of support services for Defence platforms involves the selling of the availability of one or more systems. The provider's profitability is dependent upon its ability to ensure high levels of availability over a long period of time (years). Traditionally this is made through the accumulation of components into warehouses within the platform. With a support service system based on AM, stocks of components can be reduced dramatically; this is due to the ability of the system to print the required component only when it is necessary. AM is particularly suitable for this application because it has the ability to process randomly any geometry without the need for adapting the manufacturing system to particular features of the component (no impact on setup activities). This aspect is able to cope with the randomness of failure rates of systems within the platform. As the components are printed in-platform, the lead time is reduced dramatically. Moreover, material efficiency and low Buyto-Fly ratios of AM, leads to the conclusion that AM has a major advantage over subtractive manufacturing by providing better usage of materials. This aspect outlines the suitability of the technology for applications in Defence, Aerospace and Medical industry where advanced materials may reach high costs. Finally, the last part of the review outlined that the equation of availability might be improved in two different ways. An internal way is the optimisation of the reliability of the component and the reduction of time to maintain. An external way is the reduction of the delivery time which is affected by the procurement delay and the supply of the part. As AM is an enabler of delocalised and rapid manufacturing it is concluded that the technology is able to optimise availability of systems through the in-field production of the component on demand.

The review allowed the authors to note that current AM cost models do not address consistently the challenges provided by the aleatory nature of support services. Defence Support Services are characterised by a stochastic operating environment and 
featured by uncertainty, variability and randomness which needs to be modelled and added to the final model of the system. Examples of these features are human variability, failures of machines and quality failures, variance in cycle times, variance in the skills of the operators and finally fatigue effects on worker performance (Al-Zuheri et al., 2012). Uncertainty refers to a "lack of knowledge" a sort of "human ambiguity" which implies a risk. Risk refers to a special kind of uncertainty in which the outcome of the event has negative implications. From the literature two types of uncertainty have been identified, Aleatory and Epistemic. Aleatory uncertainty is the most challenging one as neither knowledge or data can reduce it. Epistemic uncertainty is reducible through the creation of knowledge and data collection. Uncertainty occurs due to the system variability which is due to the stochastic nature of support services. It is important to model uncertainty and develop a methodology to reduce it through an increased understanding due to knowledge development (Erkoyuncu, 2011).

\section{Conclusion and Future work}

Additive Manufacturing (generic) is a disruptive technology which benefits from design freedom, short manufacturing lead times, low buy-to-fly (BTF ) ratios, complexity for free and requires limited space for operating. AM can be used for both, printing new components and repair broken ones (if combined with machining and 3D scanner). AM has the potential to reduce or eliminate sub-assemblies, access to new geometries and improve the performance of components. AM production aspects is Lean, it benefits from "pull" and "just-in-time" moreover the technology can process random geometries without any impact on setups. AM can be deployed for components, humanitarian aid, tools, repairs, temporary replacement, prosthesis, embedded sensors, drones and consumables. The review presented the various AM technologies which are currently under development in both industry and research institutes. Moreover, various available cost modelling techniques have been investigated. The discussion section provided a critical review of both, the technologies of AM and the cost modelling techniques allowing comparing and contrasting.

The main conclusion that can be deduced from the literature review are:

$>$ Powder bed technologies are more applicable to small complex geometries given their high accuracy levels.

$>$ Blown powder technologies are highly suitable for repairs but also suitable for medium to low complex geometries.

$>$ Wire fed technologies are highly suitable for large functional components given their high deposition rates.

$>$ Activity based costing seems to be the most used technique to perform product cost estimation of AM products.

$>$ There is no evidence on research of complete AM production systems which include also post processes.

To gain exhaustive understanding of AM based production systems, research institutes and industry should design an AM based system complete with all the necessary post processes and outline all the workers required and the activity involved in the whole production system in order to have a final product. This will allow to perform an actual, reliable cost estimation of additive manufacturing products.

This review helped also to outline what are the technical and operational opportunities provided by AM if applied in a Defence Support Service context, making the technology highly suitable for this sector featured and constrained by extended and disrupted supply chains.

Moreover, AM is an enabler of design freedom which provides designer the possibility to access new, more sophisticated and complex design forms. This opportunity has resulted in the large adoption of the combination of topology optimisation with AM. Through the topology optimisation of designs, firms are able to provide components with enhanced functionality such as lightweight, higher performance, reduced sub-assemblies and modularity. Another important factor to be considered in cost modelling for additive manufacturing is associated with additional design costs due to the need to re-design the part to minimize the deposition of supports and deposition time and topology optimisation.

Furthermore, the review on current AM cost models outlined that the most logical and detailed approach to costing AM products is the combination of "Activity Based Costing" (ABC) with process mapping. Nevertheless, current models do not incorporate exhaustively all the costs occurring in an end-to-end AM process, rather these focus on the solely AM deposition. Moreover, the investigated AM models do not include uncertainty and randomness which are considered rivers of costs in the real world (i.e human variability, failure rates). 


\section{Acknowledgment}

The Authors thank Dr. Richard Drake and Dr. Chris Watts of Babcock International for their contribution. This research is performed within the EPSRC Centre for Innovative Manufacturing in Through-Life Engineering Services, grant number $\mathrm{EP} / 1033246 / 1$

\section{Reference List}

Adebayo, A., 2014. Effects of solid lubricants on wire and arc additive manufactured structures. Journal of Engineering Manufacture.

Ahn, J., Ji, S.-H., Park, M., Lee, H.-S., Kim, S., Suh, S.-W., 2014. The attribute impact concept: Applications in case-based reasoning and parametric cost estimation. Automation in Construction 43, 195-203. doi:10.1016/j.autcon.2014.03.011

Al-Zuheri, A., Luong, L., Xing, K., 2012. The Role of Randomness of a Manual Assembly Line with Walking Workers on Model Validation. Procedia CIRP 3, 233-238.

An, S.-H., Kim, G.-H., Kang, K.-I., 2007. A case-based reasoning cost estimating model using experience by analytic hierarchy process. Building and Environment 42, 2573-2579. doi:10.1016/j.buildenv.2006.06.007

Arcam AB, 2014. Electron Beam Melting - EBM Process, Additive Manufacturing. Arcam AB.

ASME, 2012. Proceedings of the ASME International Manufacturing Science and Engineering Conference--2012: presented at ASME 2012 International Manufacturing Science and Engineering Conference, June 4-8, 2012, Notre Dame, Indiana, USA. American Society of Mechanical Engineers, New York, N.Y.

ASTM, 2013. Standard Terminology for Additive Manufacturing Technologies (No. F2792-12a). ASTM International.

Baumers, M., 2012. Economic aspects of Additive Manufacturing: benefits, costs and energy consumption.

Bernet, N., Wakeman, M.D., Bourban, P.-E., Månson, J.-A.E., 2002. An integrated cost and consolidation model for commingled yarn based composites. Composites Part A: Applied Science and Manufacturing 33, 495-506. doi:10.1016/S1359-835X(01)00140-3

Candel, J.J., Jimenez, J.A., Franconetti, P., Amigó, V., 2014. Effect of laser irradiation on failure mechanism of TiCp reinforced titanium composite coating produced by laser cladding. Journal of Materials Processing Technology 214, $2325-2332$. doi:10.1016/j.jmatprotec.2014.04.035

Carli, G., Canavari, M., 2013. Introducing Direct Costing and Activity based Costing in a Farm Management System: A Conceptual Model. Procedia Technology 8, 397-405. doi:10.1016/j.protcy.2013.11.052

Cavalieri, S., Maccarrone, P., Pinto, R., 2004a. Parametric vs. neural network models for the estimation of production costs: A case study in the automotive industry. International Journal of Production Economics 91, 165-177. doi:10.1016/j.ijpe.2003.08.005

Cavalieri, S., Maccarrone, P., Pinto, R., 2004b. Parametric vs. neural network models for the estimation of production costs: A case study in the automotive industry. International Journal of Production Economics 91, 165-177. doi:10.1016/j.ijpe.2003.08.005

Chen, J., 2012. Hybrid Design based on Wire and Arc Additive manufacturing in the Aircraft Industry. Crnafield University.

Colegrove, P.A., Coules, H.E., Fairman, J., Martina, F., Kashoob, T., Mamash, H., Cozzolino, L.D., 2013. Microstructure and residual stress improvement in wire and arc additively manufactured parts through high-pressure rolling. Journal of Materials Processing Technology 213, 1782-1791. doi:10.1016/j.jmatprotec.2013.04.012

Ding, J., Colegrove, P., Mehnen, J., Ganguly, S., Sequeira Almeida, P.M., Wang, F., Williams, S., 2011. Thermo-mechanical analysis of Wire and Arc Additive Layer Manufacturing process on large multi-layer parts. Computational Materials Science. doi:10.1016/j.commatsci.2011.06.023

Duran, O., Maciel, J., Rodriguez, N., 2012. Comparisons between two types of neural networks for manufacturing cost estimation of piping elements. Expert Systems with Applications 39, 7788-7795. doi:10.1016/j.eswa.2012.01.095

Erkoyuncu, J.A., 2011. Cost Uncertainty Management and Modelling for Industrial Product-Service Systems.

Fraunhofer, 2014. Ihr Partner für Innovationen - Fraunhofer ILT [WWW Document]. URL http://www.ilt.fraunhofer.de/ (accessed 7.23.14).

Gayretli, A., Abdalla, H.S., 1999. An object-oriented constraints-based system for concurrent product development. Robotics and Computer-Integrated Manufacturing 15, 133-144. doi:10.1016/S0736-5845(99)00007-1

Gibson, I., 2010. Additive manufacturing technologies: rapid prototyping to direct digital manufacturing. Springer, London ; New York.

Gao, Wei, Yunbo Zhang, Devarajan Ramanujan, Karthik Ramani, Yong Chen, Christopher B. Williams, Charlie C.L. Wang, Yung C. Shin, Song Zhang, and Pablo D. Zavattieri. "The Status, Challenges, and Future of Additive Manufacturing in Engineering." Computer-Aided Design 69 (December 2015): 65-89. doi:10.1016/j.cad.2015.04.001. 
Hopkinson, N., Dickens, P., 2003. Analysis of rapid manufacturing-using layer manufacturing processes for production. Proceedings of the Institution of Mechanical Engineers, Part C: Journal of Mechanical Engineering Science 217, 3139. doi:10.1243/095440603762554596

Ivanova, O., Williams, C., Campbell, T., 2013. Additive manufacturing (AM) and nanotechnology: promises and challenges. Rapid Prototyping Journal 19, 353-364. doi:10.1108/RPJ-12-2011-0127

Kiritsis, D., Neuendorf, K.-P., Xirouchakis, P., 1999. Petri net techniques for process planning cost estimation. Advances in Engineering Software 30, 375-387. doi:10.1016/S0965-9978(98)00126-4

Lindemann, 2012. Analyzing Product Lifecycle Costs for a Better Understanding of Cost Drivers in Additive Manufacturing.

Loeber, 1., Biamino, S., 2011. Comparison of Selective Laser and Electron Ceam Melted Titanium Aluminides. Leibniz Institute fro Solid State and Materials Research.

Man-Yi Chen, Ding-Fang Chen, 2002. Early cost estimation of strip-steel coiler using BP neural network. IEEE, pp. 13261331. doi:10.1109/ICMLC.2002.1167420

Martina, F., 2014. Wire and Arc Additive Manufacturing (Cranfield Prensentation). Cranfield University.

Martina, F., Colegrove, P.A., Williams, S.W., Meyer, J., 2015. Microstructure of Interpass Rolled Wire + Arc Additive Manufacturing Ti-6Al-4V Components. Metallurgical and Materials Transactions A. doi:10.1007/s11661-015-31721

Martina, F., Mehnen, J., Williams, S.W., Colegrove, P., Wang, F., 2012. Investigation of the benefits of plasma deposition for the additive layer manufacture of Ti-6Al-4V. Journal of Materials Processing Technology 212, $1377-1386$. doi:10.1016/j.jmatprotec.2012.02.002

Mellor, S., Hao, L., Zhang, D., 2014. Additive manufacturing: A framework for implementation. International Journal of Production Economics 149, 194-201. doi:10.1016/j.ijpe.2013.07.008

NASA, 2014. Additive Manufacturing Modeling and Simulation (Literature Review No. NASA/TM-2014-218245). NASA, Hanover.

Niazi, A., Dai, J.S., Balabani, S., Seneviratne, L., 2006. Product Cost Estimation: Technique Classification and Methodology Review. Journal of Manufacturing Science and Engineering 128, 563. doi:10.1115/1.2137750

Pahl, G., Wallace, K., Blessing, L., Pahl, G. (Eds.), 2007. Engineering design: a systematic approach, 3rd ed. ed. Springer, London.

QIU, X., 2014. EFFECT OF ROLLING ON FATIGUE CRACK GROWTH RATE OF WIRE AND ARC ADDITIVE MANUFACTURE (WAAM) PROCESSED TITANIUM. Cranfield University.

Rafi, H.K., Karthik, N.V., Gong, H., Starr, T.L., Stucker, B.E., 2013. Microstructures and Mechanical Properties of Ti6A14V Parts Fabricated by Selective Laser Melting and Electron Beam Melting. Journal of Materials Engineering and Performance 22, 3872-3883. doi:10.1007/s11665-013-0658-0

RAND, 2013. Future Technology Landscapes. RAND Europe, Cambridge.

Rehman, S., Guenov, M.D., 1998. A methodology for modelling manufacturing costs at conceptual design. Computers \& Industrial Engineering 35, 623-626. doi:10.1016/S0360-8352(98)00174-0

Roland Berger, 2013. Additive Manufacturing. Roland Berger, Munich.

Ruffo, M., Hague, R., 2007. Cost estimation for rapid manufacturing — simultaneous production of mixed components using laser sintering. Proceedings of the Institution of Mechanical Engineers, Part B: Journal of Engineering Manufacture 221, 1585-1591. doi:10.1243/09544054JEM894

Safdar, S., Li, L., Sheikh, M.A., 2007. Numerical analysis of the effects of non-conventional laser beam geometries during laser melting of metallic materials. Journal of Physics D: Applied Physics 40, 593-603. doi:10.1088/0022$3727 / 40 / 2 / 039$

Saqib, S., Urbanic, R.J., Aggarwal, K., 2014. Analysis of Laser Cladding Bead Morphology for Developing Additive Manufacturing Travel Paths. Procedia CIRP 17, 824-829. doi:10.1016/j.procir.2014.01.098

Seufzer, B., 2013. Automating Electron Beam Free Form Fabrication with MATLAB.

Sfantsikopoulos, M.M., Diplaris, S.C., Papazoglou, P.N., 1995. Concurrent dimensioning for accuracy and cost. The International Journal of Advanced Manufacturing Technology 10, 263-268. doi:10.1007/BF01186877

Shehab, E.., Abdalla, H.., 2001. Manufacturing cost modelling for concurrent product development. Robotics and ComputerIntegrated Manufacturing 17, 341-353. doi:10.1016/S0736-5845(01)00009-6

Shehab, E.M., Abdalla, H.S., 2002. A design to cost system for innovative product development. Proceedings of the Institution of Mechanical Engineers, Part B: Journal of Engineering Manufacture 216, 999-1019. doi:10.1243/09544050260174201

Singh, N., 2002. Integrated product and process design: a multi-objective modeling framework. Robotics and ComputerIntegrated Manufacturing 18, 157-168. doi:10.1016/S0736-5845(01)00030-8

Son, Y.K., 1991. A cost estimation model for advanced manufacturing systems. International Journal of Production Research 29, 441-452. doi:10.1080/00207549108930081 
Stecker, S., 2013. ADVANCED ELECTRON BEAM FREE FORM FABRICATION METHODS \& TECHNOLOGY.

Taminger, T., 2014. Electron Beam Additive Manufacturing. NASA.

Taminger, T., Hafley, R., 2010. Electron Beam Free Form Fabrication: A Rapid Deposition Process. NASA.

Thomas, D.S., Gilbert, S.W., 2014. Costs and Cost Effectiveness of Additive Manufacturing (No. NIST SP 1176). National Institute of Standards and Technology.

Tong, Z., Zhentai, Z., Rui, Z., 2013. A dynamic welding heat source model in pulsed current gas tungsten arc welding. Journal of Materials Processing Technology 213, 2329-2338. doi:10.1016/j.jmatprotec.2013.07.007

US Navy, 2015. US Navy is 3D Printing Custom Drones Onboard the USS Essex - 3DPrint.com [WWW Document]. URL http://3dprint.com/85654/us-navy-3d-printed-drones/ (accessed 10.21.15).

Verlinden, B., Duflou, J.R., Collin, P., Cattrysse, D., 2008. Cost estimation for sheet metal parts using multiple regression and artificial neural networks: A case study. International Journal of Production Economics 111, 484-492. doi:10.1016/j.ijpe.2007.02.004

Vouk, D., Malus, D., Halkijevic, I., 2011. Neural networks in economic analyses of wastewater systems. Expert Systems with Applications 38, 10031-10035. doi:10.1016/j.eswa.2011.02.014

Wang, F., Williams, S., Rush, M., 2011. Morphology investigation on direct current pulsed gas tungsten arc welded additive layer manufactured Ti6Al4V alloy. The International Journal of Advanced Manufacturing Technology 57, $597-603$. doi:10.1007/s00170-011-3299-1

Zhai, Y., 2012. Early Cost Estimation fro Additive Manufacture. Cranfield University. 
2017-08-08

\title{
A review of additive manufacturing technology and cost estimation techniques for the defence sector
}

\section{Busachi, Alessandro}

Elsevier

\begin{abstract}
Alessandro Busachi, John Erkoyuncu, Paul Colegrove, Filomeno Martina, Chris Watts, Richard Drake, A review of Additive Manufacturing technology and Cost Estimation techniques for the defence sector, CIRP Journal of Manufacturing Science and Technology, Volume 19, November 2017, Pages 117-128
\end{abstract}

http://dx.doi.org/10.1016/j.cirpj.2017.07.001

Downloaded from Cranfield Library Services E-Repository 